\title{
The Impact of the Mathematics S-STEM Program at the University of Texas at Arlington
}

\section{Prof. Tuncay Aktosun, University of Texas at Arlington}

Dr. Aktosun is a professor of mathematics at the University of Texas at Arlington. His research area is applied mathematics and differential equations with research interests in scattering and spectral theory, inverse problems, wave propagation, and integrable evolution equations. He is involved in various mentoring and scholarship programs benefiting students. He has been the GAANN Fellowship Director in his department since 2006, the NSF S-STEM Scholarship Director in his department since 2008, and he also acts as the Project Director for the NSF Bridge Program in his department. In the past he served as the Graduate Director and as the Undergraduate Director in his department, and he directed the NSF-LSAMP program on his campus during 2009-2014 and also directed the NSF-LSAMP Bridge-to-Doctorate program on his campus during 2010-2013.

\section{Prof. Jianzhong Su, University of Texas at Arlington}

Dr. Jianzhong Su is professor and chair of Mathematics at the Department of Mathematics, University of Texas at Arlington. He received his Ph.D. in 1990 from University of Minnesota under Professor Hans Weinberger and he has been in higher education for over 27 years. He is an applied mathematician with research areas in partial differential equations and dynamical systems, with a particular interest in problems from computational neuroscience. He has graduated 10 doctoral students, and is very involved student mentoring of undergraduate students and high school students. 


\section{THE IMPACT OF THE MATHEMATICS S-STEM PROGRAM AT THE UNIVERSITY OF TEXAS AT ARLINGTON}

\section{INTRODUCTION}

The University of Texas at Arlington (UTA) is one of the eight campuses in the University of Texas system, and it is the second largest campus after the flagship campus at Austin. It offers bachelor's, master's, and doctoral degrees. In the fall semester of 2017 it had an enrollment of 47,535 students with a sharp increase from the enrollment of 39,819 in the fall of 2016.

\begin{tabular}{|l|l|l|}
\hline $62.3 \%$ women & $88.4 \%$ domestic & $72.1 \%$ undergraduate \\
\hline $37.7 \%$ men & $11.6 \%$ international & $27.9 \%$ graduate \\
\hline
\end{tabular}

Table 1. The enrollment data of 47,535 students at UTA in the fall of 2017

Of the 47,535 students enrolled in the fall of 2017, 62.3\% were women and $37.7 \%$ were men. These percentages are not uniform in all the disciplines, as the percentage of women in some engineering programs at UTA is very low. Among the 47,435 students enrolled in the fall of 2017, 42,032 (88.4\%) were domestic students and 5,503 (11.6\%) were international students. There were 34,261 undergraduate students and 13,274 graduate students, making up 72.1\% and $27.9 \%$ of the student population of 47,535 , respectively. There were 19,777 URMs (underrepresented minorities, i.e. African Americans, American Indians including Native Alaskans, Hispanics and Native Pacific Islanders), and that number constituted $47.1 \%$ of the domestic students. Among the 34,261 undergraduate students, 61.6\% were women and 38.4\% were men; among the 13,274 graduate students, $64.2 \%$ were women and 35.8\% were men. In contrast, among the 5,503 international students, $20.0 \%$ were women and $80.0 \%$ were men. Among the 19,777 URMs, 56.8\% were Hispanic, 34.6\% were African American, and 8.6\% belonged to other or multiple URM groups. Among the 42,032 domestic students, 26.7\% were Hispanic, 16.3\% were African American, and 11.1\% were Asian.

\begin{tabular}{|c|c|c|c|}
\hline 34,261 undergraduate & 13,274 graduate & 5,503 international & 42,032 domestic \\
\hline $61.6 \%$ women & $64.2 \%$ women & $20 \%$ women & $47 \%$ URMs \\
\hline $38.4 \%$ men & $35.8 \%$ men & $80 \%$ men & $53 \%$ non-URMs \\
\hline
\end{tabular}

Table 2. The enrollment data of 47,535 students at UTA in the fall of 2017 
The UTA Mathematics Department offers bachelor's, master's, and doctoral degrees. In the fall semester of 2017 it had 25 faculty, 120 graduate students, and 272 undergraduate mathematics majors. Among the 120 graduate students there were $71 \mathrm{PhD}$ students and 49 master's students, $50 \%$ women and $50 \%$ men, $71 \%$ domestic students and $29 \%$ international students. Among the 120 graduate students there were 42 URMs, making up 35\% of all mathematics graduate students and $49.4 \%$ of the domestic mathematics graduate students. In contrast, the 2014 data [1] indicates that $55 \%$ of the $\mathrm{PhD}$ students in the mathematical sciences in the U.S. were domestic students and $45 \%$ were international students. Furthermore, only $11 \%$ of the domestic $\mathrm{PhD}$ students in the mathematical sciences in the U.S. were URMs. The same data show that $49 \%$ of the $\mathrm{PhD}$ degree recipients in the U.S. during the academic year 2013-2014 were domestic students, $51 \%$ were international students, and only $8.8 \%$ of the domestic $\mathrm{PhD}$ degree recipients were URMs. In contrast, since 2008 in the UTA Mathematics Department, 56\% of the PhD degree recipients were domestic students, $44 \%$ were international students, and $25 \%$ of the domestic PhD degree recipients were URMs.

\begin{tabular}{|l|l|l|}
\hline 71 doctoral & $71 \%$ domestic & $50 \%$ women \\
\hline 49 master's & $29 \%$ international & $50 \%$ men \\
\hline
\end{tabular}

Table 3. The data for 120 graduate students in the UTA Math Department in the fall of 2017 Among the 272 UTA undergraduate mathematics majors, $45.2 \%$ were women and 54.8\% were men, $93.4 \%$ were domestic students and $6.6 \%$ were international students. Among the 272 UTA undergraduate mathematics majors there were 103 URMs, constituting $40.1 \%$ of the domestic undergraduate mathematics majors. The current one-year retention rates in the UTA Mathematics Department are $77.8 \%$ for first-time-in-college undergraduate students and $70.0 \%$ for new transfer undergraduate students from a community college, respectively. The average one-year retention rate for new undergraduate students in the UTA Mathematics Department is $72.9 \%$.

\begin{tabular}{|c|c|c|}
\hline 272 math majors & 272 math majors & 254 domestic math majors \\
\hline $45.2 \%$ women & $93.4 \%$ domestic & $40.1 \%$ URMs \\
\hline $54.8 \%$ men & $6.6 \%$ international & $59.9 \%$ non-URMs \\
\hline
\end{tabular}

Table 4. The data for 272 UTA mathematics majors in the fall of 2017 
The first author is a professor of mathematics at UTA and acts as the PI and Director for the Mathematics S-STEM program in his department. He arrived at UTA in the fall semester of 2005 as a tenured full professor of mathematics. The corresponding data in the UTA Mathematics Department in the fall of 2005 were much different from the data in the fall of 2017. For example, there were 29 mathematics faculty members in 2005, and efforts were under way to increase that number to 35. The number of doctoral students in the UTA Mathematics Department in 2005 was about one third of the corresponding number in 2017. The average annual number of PhD degrees awarded in the UTA Mathematics Department in 2005 was about three, and that number is more than tripled now. The number and percentage of domestic doctoral students were very small in 2005, and the only financial support available to UTA doctoral mathematics students at that time was through graduate teaching assistantships. In 2005 almost all of the financial support available to mathematics graduate students went to international students, resulting in very few domestic doctoral students and hardly any URM doctoral students in the UTA Mathematics Department. Thanks to several external doctoral fellowships awarded to the UTA Mathematics Department by the NSF (National Science Foundation) and the U.S. Education Department, the number and percentage of domestic students in the UTA Mathematics Department have grown drastically. Since 2005 the UTA Mathematics Department also started getting a large number of international doctoral students that are being supported by their own governments. The external doctoral fellowships for domestic students and the support for international students by their own governments have helped the doctoral program in the UTA Mathematics Department grow drastically, with some increase in the number of international students, a sharp increase in the number of domestic doctoral students, and a very steep increase in the number of URM doctoral students. For example, the data from September 2017 have indicated that the GAANN (Graduate Assistance in Areas of National Need) fellowship program, which has been supported by four consecutive grants awarded to the UTA Mathematics Department by the U.S. Education Department since 2006, has supported 52 doctoral students as GAANN fellows. Of 52 supported GAANN fellows, 36 received their PhD degrees during the period of May 2008-August 2017, and 11 of those 36 $\mathrm{PhD}$ recipients were URMs. Among the 14 continuing GAANN fellows there are 6 URMs, and all of 14 continuing GAANN fellows are making timely progress toward their PhD degrees. 
The fruitful efforts at the doctoral level in the UTA Mathematics Department have been coupled with efforts at the undergraduate level. There also have been efforts to establish strong links with area middle schools and high schools and civic organizations, with the goal of helping middle and high school students learn about careers in the mathematical sciences and encouraging them to attend college. All such efforts have resulted in positive changes at every level, and the UTA Mathematics Department was recognized nationally in 2013 by the AMS (American Mathematical Society) as the winner of the AMS Award for an Exemplary Program or Achievement by a Mathematics Department. A description of such efforts can be read in the four-page article [2] authored by Allyn Jackson of the American Mathematical Society. In this paper we present a description of our S-STEM program in the UTA Mathematics Department. Our program has been funded by the NSF Division of the Undergraduate Education, and we have been running it continuously since the fall semester of 2008. We describe how our S-STEM program has positively affected our undergraduate mathematics program in general. We discuss the improvements we have made to increase the impact of our S-STEM funding. We also share the lessons we have learned to effectively run our S-STEM program despite the limited faculty resources.

\section{THE MATHEMATICS S-STEM PROGRAM}

Our first S-STEM grant from the NSF Division of Undergraduate Education was awarded to the UTA Mathematics Department in 2008. It was DUE-0807110 with a total budget of $\$ 483,000$, and it covered the period of June 1, 2008-May 31, 2013. The number of scholarship recipients was 46, 24 (52\%) of whom were transfer students from two-year community colleges. Two students (4.3\%) left the program without getting a degree, but 44 recipients (95.7\%) received a bachelor's degree (not all necessarily within four years). The UTA Mathematics Department received its second S-STEM grant DUE-1260019 in 2013 from the NSF Division of Undergraduate Education. The total budget was $\$ 623,608$, and the grant covered the period of September 1, 2013-August 31, 2018. During the transition period from our first S-STEM grant to our second S-STEM grant, several students who started receiving support from the first grant continued receiving support from the second grant without violating any NSF rules. As of December 2017, by these two S-STEM grants, a total of 84 undergraduate mathematics majors have been supported but two left without receiving a bachelor's degree, 73 of them have received 
their bachelor's degrees, and the remaining nine students are making timely progress toward their degrees. Among the 73 degree recipients in our S-STEM program there were 30 women (41\%) and 43 men (49\%) and 22 URMs (30\% of the degree recipients). Among the nine continuing S-STEM scholars there are five women and four men and three URMs. Those nine current S-STEM scholars will continue to be supported in the spring semester of 2018 and beyond until they receive their bachelor's degrees. Our third S-STEM grant application to NSF has been recommended for funding by the NSF program officer with the start date of April 1, 2018, and we are waiting for the official approval by NSF.

\begin{tabular}{|l|l|}
\hline 73 degree recipients & 9 continuing \\
\hline $41 \%$ women & $55.5 \%$ women \\
49\% men & $44.5 \%$ men \\
$30 \%$ URMs & $33.3 \%$ URMs \\
\hline
\end{tabular}

Table 5. The supported student data in the UTA Math S-STEM program during 2008-2017

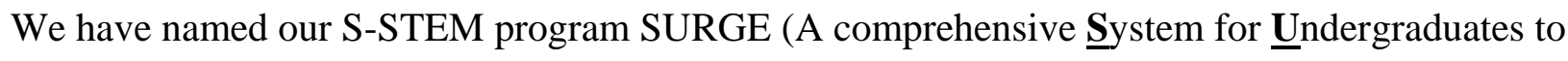
$\underline{\text { Reach }}$ Goals in Education). The objectives of our SURGE program have been:

- To improve educational opportunities for mathematically-talented and financially-needy students in the UTA Mathematics Department by providing them with S-STEM scholarships. The students are admitted in cohorts, each student can receive up to $\$ 10,000$ per year in general for up to three years of support. In practice, we support our S-STEM scholars until they receive their bachelor's degrees in a timely manner, contingent upon good academic progress, availability of funds, and financial eligibility determined by FAFSA (Free Application for Federal Student Aid).

- To provide academic support to S-STEM scholars so that they complete their bachelor's degrees in a timely manner.

- To help the S-STEM scholars prepare to enter STEM workforce or to continue to graduate school.

- To fully utilize student support programs at UTA that benefit all mathematics majors.

- To enhance the pipeline for mathematically-talented community college students who transition to UTA to receive their bachelor's degrees. 
We are in a unique position to accomplish these objectives successfully through a coherent team effort that builds on the following:

- UTA is located in the Dallas-Fort Worth metropolitan area containing the cities of Dallas and Fort Worth. This metropolitan area has a total population of over 6.5 million people. We have a large local pool of academically-talented and financially-needy students at UTA and at the two community college systems in Dallas County and Tarrant County, respectively, from which we can recruit recipients for our SURGE scholarships. One of these community college systems is DCCCD (Dallas County Community College District), and it has seven campuses. The other community college system is TCCD (Tarrant County College District), and it has five campuses. These two community college systems have a total enrollment of 130,000. The seven DCCCD campuses are located in Dallas and the surrounding areas and the five TCCD campuses are located in Fort Worth and the surrounding areas.

- An existing active mathematics learning community anchored by the UTA Student Chapter of the MAA (Mathematical Association of America), on which we have built strong support programs to ensure academic success and professional development for our SURGE scholars.

- An institutional initiative to improve undergraduate retention and graduation rates, which overlaps well with the SURGE program in goals and plans.

- A vibrant regional economy that provides ample opportunities to place our SURGE scholars in internships and permanent jobs. Many of our SURGE alumni work at major corporations in the region. They are great assets to our SURGE scholars for career mentoring and job placement.

The MAA Student Chapter in the UTA Mathematics Department was formed in 2002, and it is a key component of our active mathematics learning community. Currently it has 130 active student members, and that number is roughly half of the number of UTA mathematics majors. The average number of the SURGE scholars has been 20, which is about $7 \%$ of all UTA mathematics majors and about 15\% of the MAA Chapter members. All of our SURGE scholars are very active in the MAA Student Chapter, and they hold key leadership positions there. 
Over the last ten years, our MAA Chapter has become a great venue for mathematics majors to interact with faculty, build a peer support network, develop study skills, enhance professional development, perform community services, organize social activities, gain leadership skills, and prepare for careers after graduation. In 2014, our MAA Chapter received the UTA Outstanding Student Organization Award in recognition of its successes. The SURGE program has been fully utilizing the MAA Chapter community. All of our SURGE scholarship recipients are required to join our MAA Chapter and participate in its biweekly lunch meetings. They are also encouraged to participate in other activities organized by the MAA Student Chapter based on their interests and time availability. As a part of this active learning community, SURGE students make academic and social progress and act as good role models for all UTA mathematics majors.

The MAA Chapter organizes biweekly lunch meetings during 12:00 noon-12:50 pm on the first and third Wednesday of each month. That time period on Wednesdays at UTA is reserved for student development, and no regular classes are scheduled during that period. At the MAA lunch meetings, students and faculty interact, plans are made for future activities, invited speakers give presentations, and panelists discuss various topics. Those lunch meetings also allow us to recruit future SURGE scholars to our program.

Representatives from local companies are usually invited to MAA lunch meetings to discuss industrial applications of mathematics and career opportunities for mathematics majors. Graduate students are also invited to give presentations at these lunch meetings on their research and to share their experiences on how to succeed in graduate school. Our department and institution emphasize integration of learning with community services to develop students' sense of civic responsibilities. Our MAA Chapter students have been actively participating in community services such as tutoring middle and high school students, organizing various math camps for area students, and hosting middle and high school students to visit our campus.

Our MAA Chapter students, including our SURGE scholars, regularly participate in various mathematics contests, such as the Putnam Exam, the Problem Solving Competition, and some other competitions at regional or national mathematics conferences. Our students usually perform well in those contests. For example, they won the Math Jeopardy contest at the 2007 MathFest in San Jose and a best student research poster award in the 2016 Joint Mathematics Meeting in Seattle. Our MAA Chapter students regularly attend AMS and MAA meetings of the 
as well as various regional and national undergraduate research conferences organized by other organizations. About 30 of our undergraduate mathematics majors attend various national and regional conferences each year. Travel funds come from various sources including student fundraisings, conference organizers, grants from professional societies, faculty grants, and department and university support. Our SURGE program has funds to cover the conference travel expenses of the SURGE scholars.

Our SURGE scholars are also active in the AWM (Association for Women in Mathematics) Student Chapter in our department. The membership in the AWM Chapter is open to everyone including men, and currently there are over 50 active members. The purpose of the AWM Chapter is to encourage women and girls to study and to have active careers in the mathematical sciences and to promote equal opportunity and the equal treatment of women and girls in the mathematical sciences. The AWM Chapter organizes biweekly lunch meetings during 12:00 noon-12:50 pm on the second and fourth Wednesday of each month, and all our SURGE scholars participate in those lunch meetings. In 2017 the AWM Chapter at UTA won the inaugural national AWM award for fundraising and sustainability.

The UTA support programs provide a wide variety of services including career workshops, counseling, tutoring, and writing skill enhancement. At the university level, UTA offers various support programs that complement the programs offered by the Mathematics Department. Of particular importance to the SURGE scholars are the Financial Aid Office, Student Success Programs, Office of Information Technology Client Services, Career Services, and Counseling Services. For the SURGE scholars to learn about and to utilize these existing university support programs, we usually invite staff from each of these service units to give presentations to each cohort of S-STEM students. The UTA Financial Aid Office determines students' eligibility for financial aid and disburses the financial aid to students' accounts. We closely work with this office to determine each SURGE student's financial need level based on his/her FAFSA submission and other financial support the student is receiving. Since 2006, our department has had an excellent working relationship with this office through its four U.S. Education Department GAANN fellowship grants and four major NSF scholarship grants.

UTA offers various student success programs to improve retention and graduation rate. In particular, the SOAR (Students Obtain Academic Readiness) program and the Writing Center 
are of special interest to our SURGE scholars. The SOAR program provides personal tutoring on a wide range of core courses required for graduation, from humanity to social sciences to natural sciences. The tutoring service is free to financially needy or first-generation college students. This complements the services provided by the Math Clinic in our department that focuses on free personal tutoring for mathematics classes. It also offers supplemental instruction, course reviews, study groups, graduate school preparation, and other support services. We remark that the SOAR program was replaced by the IDEAS (Innovation, Diversity, Excellence, Access, Success) Center in 2015, and the IDEAS Center continues to provide similar services to transfer students, veterans, sophomores, and students re-entering school after a break, to help pave a path to student success. It offers free tutoring and mentoring. The Writing Center provides free oneon-one and online services to help UTA students improve their writing skills. Our SURGE faculty mentors closely follow the academic progress of the SURGE scholars and refer them to the UTA support programs as needed.

The University Career Services at UTA offers a broad range of services to UTA students. It helps students locate internship opportunities and organizes various career/job/professional and graduate school fairs. It also offers a series of workshops on the following topics:

- Interests: determining career interests and work preferences

- Skills: identifying skill sets and abilities

- Resume Writing: documenting accomplishments

- Job Search Strategies I: creating a 60-second video and developing a plan for networking

- Job Search Strategies II: learning how to communicate in writing during a job search

- Interview Skills: common interview formats and preparing for interviews

These workshops are offered at various times and days to fit students' schedules. We encourage all our SURGE scholars to complete this workshop series during their senior year.

The University Counseling Services office at UTA provides free services helping students succeed in their classes, careers, and personal lives. It helps students adjust to college and balance obligations. One-on-one, confidential personal counseling sessions are offered by appointment or walk-in. This office also periodically offers workshops and seminars on a variety of topics, including resilience, time management, improving study skills, reducing test anxiety, improving memory, overcoming public speaking anxiety, and managing stress. We closely 
monitor the progress of our SURGE scholars and, if needed, either refer them to this office for individual help or invite staff from this office to organize workshops on select topics of interest to our SURGE scholars.

Our SURGE program ensures that each SURGE scholar has a personal faculty mentor meeting with the student regularly in order to closely follow his/her academic and professional progress and to identify potential problems at an early stage so that corrective measures can be taken in a timely manner. We have established a peer mentoring aspect in our SURGE program. We have two experienced senior mathematics majors and two experienced mathematics doctoral students acting as student mentors to our SURGE scholars. These peer mentors provide information on classes, study skills, student community, and graduate schools from a student perspective. We have also established an industrial mentoring aspect in our SURGE program. The industrial mentoring in our SURGE program relies on expertise and experience of working professionals at major corporations in the Dallas-Fort Worth area. The industrial mentors serve as external career mentors to our SURGE scholars, and they meet with the SURGE scholars on various occasions to advise them on launching successful careers, provide them with information on internship opportunities, and alert them of job openings.

In the near future we plan on adding another mentoring aspect in our SURGE program. Especially for those SURGE scholars who transition to UTA from a community college, we plan to have a faculty mentor from the former community college. Our SURGE program has recently built a network of community college faculty mentors at TCCD and DCCCD. We plan to have various monthly joint activities with TCCD and DCCCD mentors and students such as seminars, research presentations, and campus visits. The community college faculty mentors will add a significant element to extend our SURGE mentoring system. The added element will allow the community college faculty to maintain their interactions with their former students. It will improve the retention and timely graduation of our SURGE scholars transferring from a community college.

\section{THE LESSONS LEARNED}

Having run various scholarship and fellowship programs in our department, we have gained some valuable experiences, which have helped us use our resources in an optimal way. We would like to share some of our practices that work well for us. 
In admitting any student to our S-STEM program, besides checking all the credentials of the applicants carefully and ensuring that the student meets our expected admission criteria, we ask ourselves three key questions:

- Will the student receive a mathematics bachelor's degree?

- Will the student receive a mathematics bachelor's degree from UTA?

- Will the student receive a mathematics bachelor's degree from UTA in a timely manner? These three questions allow us to make a good risk analysis in admitting a student to our SURGE program, to assess the student's resilience and seriousness to receive a mathematics bachelor's degree from UTA in a timely manner, and to determine the student's strengths and weaknesses. These three questions have played a key role for us to optimally manage the financial and human resources in our SURGE program.

We do not admit a student into our SURGE program if we feel that the student does not have a serious intention of receiving a mathematics bachelor's degree from UTA or that the student may intentionally and unnecessarily prolong the time to the degree. For example, if a student is interested in receiving a degree in another field and does not intend to receive a degree in mathematics and simply takes some low-level mathematics courses just to benefit from the financial aspect of our SURGE program, we would not want to admit that student into our program. We feel that such a student should seek a scholarship from the department related to the student's major. We would not want to admit into our SURGE program a student who wastes resources by not concentrating on major studies, by not taking serious major courses, or by delaying graduation intentionally without any good reasons. We work very closely with the undergraduate academic advisor in the UTA Mathematics Department to ensure that each undergraduate mathematics major receives the best plan for coursework and timely graduation. We understand that it may take longer for some students to receive their degrees and that some students may need to make up for their deficiencies to strengthen their background. We certainly help such students and ensure that they strengthen their mathematics background to succeed in their advanced courses.

Many of the undergraduate students at UTA are transfer students from community colleges, and the main reason behind this is financial. Those transfer students mostly come from the DCCCD 
and TCCD campuses. According to the data from the fall of 2016, the enrollment at community colleges has far outpaced that at four-year public universities in the Dallas-Forth area. In the fall of 2016 the enrollments at DCCCD, TCCD, and UTA were 72,766 undergraduate students, 49,107 undergraduate students, and 39,819 (72\% undergraduate and 28\% graduate) students, respectively. In the fall of 2016, the tuition for 12 credits per semester at DCCCD, TCCD, and UTA was $\$ 608, \$ 796$, and $\$ 4,808$, respectively. The tuition rate at a typical Texas public university such as UTA is more than six to seven times that at TCCD or DCCCD. Many talented students from financially-needy families simply cannot afford to attend four-year colleges such as UTA [3]. In fact, many students at four-year colleges are now moving to two-year colleges due to financial difficulties [4]. About $84 \%$ of the UTA mathematics majors received financial support during the 2016-2017 academic year, and after that financial support their average unmet financial need was still \$5,769. This indicates the importance of our SURGE program and shows how it creates financial relief for our mathematically-talented students. The demographics for the UTA undergraduate mathematics majors are as follows:

- About $50 \%$ of our mathematics majors are transfer students from area community colleges, mostly from DCCCD and TCCD. These students usually start at UTA as sophomores. With the widening tuition gap between community colleges and UTA, we expect more students first to attend a community college and then transfer to UTA. Their one-year retention rate at UTA is $78 \%$.

- About 25\% of our mathematics majors come to UTA directly from high school and choose mathematics as their majors upon arrival at UTA. These students typically have enough AP (Advanced Placement) college credits in mathematics to begin immediately the second-year mathematics curriculum. Their one-year retention rate is $70 \%$.

- The final $25 \%$ of our mathematics majors are undecided when they arrive at UTA. They are attracted to mathematics programs while taking mathematics classes, typically the calculus sequence. They usually become mathematics majors in their second year at UTA. The retention rate is not applicable here because only retained students will choose mathematics as their major.

The research conducted in the fall semester of 2016 by our institution has indicated that the transfer students in STEM fields from TCCD has a distinctively higher success rate in 
mathematics courses if they transfer to UTA after their first year instead of transferring in their second year or later. The success mentioned here is measured as receiving a grade of $\mathrm{A}$ or $\mathrm{B}$ or $\mathrm{C}$ in a mathematics course in the semester the research was conducted. On the other hand, it is desirable for a community college to have a student transfer to a four-year institution only after receiving an associate degree, and this normally happens if the student spends two years in the community college. A transfer student from a community college without an associate degree from that community college does not bring much credit or recognition for the efforts made by that community college. As a result, the community colleges are reluctant to let their students move to a four-year college only after one year. The administrators at UTA and TCCD have recently signed an MOU (Memorandum of Understanding) enabling a reverse articulation, allowing TCCD to award an associate degree to a transfer student at the same time the student receives a bachelor's degree from UTA. By doing so, the appropriate credit will be given to the community college, and this will also partially reduce the financial burden on the community college. Hence, this is an optimal solution for student transition for both our department and the community college. Such reverse articulations are now considered for other community colleges in the area. A nationwide implementation of such reverse articulations could benefit students, community colleges, and four-year colleges by helping optimize the use of educational resources in the nation.

In the past a significant percentage of our SURGE scholars entered our program in their third year, but we are now making efforts to recruit most of our SURGE scholars when they are sophomores. We certainly always consider admitting exceptional students at any level. By focusing on sophomores, we plan to identify mathematically-talented students at an early stage and to assess their potential for future success sooner. This also means that we can provide threeyear financial assistance and mentoring to our SURGE scholars by the time they receive their bachelor's degrees. This necessitates the maximal use of our financial resources in the SURGE program. We simply cannot afford wasting financial resources on students who will not receive their bachelor's degrees or will not receive their bachelor's degrees in mathematics from our institution or will not receive their degrees in a timely manner. Thus, the three aforementioned key questions will continue to play an important role in the admission to our SURGE program. The NSF S-STEM funds have enabled us to attract talented students into mathematics, ease the financial burden on them as they major in mathematics, mentor them, graduate them, and help 
them move to industrial careers or to graduate studies. Over 70\% of UTA undergraduate students work out of necessity. Many work 30 or more hours per week while carrying a full course load. Even for those who are fortunate to receive financial support, typically over 60\% of their support package is student loans. To avoid becoming overly debt-ridden, many students have to work part time or full time to finance their studies at UTA. This hampers the academic progress of many of our students. Some of them take longer than normal to graduate, and some never make it to graduation. The S-STEM scholarships allow the students in the SURGE program to devote more time to study and to graduate in a timely manner.

The joint efforts by the faculty in the UTA Mathematics Department, starting in the fall semester of 2005, have resulted in many positive changes. The federal scholarship and fellowship grants secured by the Mathematics Department have enabled us to diversify our student population both at the undergraduate and graduate levels. When the first author arrived at UTA in the fall of 2005, there were very few URMs among mathematics students. Now, URMs make up 40.1\% of our domestic undergraduate mathematics majors and $49.4 \%$ of our mathematics graduate students.

Prior to 2005, the involvement of undergraduate students in research by faculty hardly existed. Undergraduate research is now a part of our departmental culture, and our faculty regularly involve undergraduate students in research. For example, the first author, in his summer research programs at UTA since 2006 has directed the research of 56 undergraduate students (45 of them were URMs). Ironically, when he ran his first NREUP (National Research Experience for Undergraduates Program) with funding from MAA and NSA (National Security Agency) in the summer of 2006, two of the four URM participants in the program had to be recruited from other institutions because there were not enough URMs among UTA mathematics majors at that time. A typical NREUP involves four local URM mathematics majors supervised by a mathematics faculty in the summer.

Undergraduate research in our department has had a drastic effect and encouraged many of our talented undergraduate mathematics majors to move to doctoral studies. It has also enabled our doctoral students to be involved in mentoring undergraduate students and helping faculty run undergraduate research programs. When the doctoral degree recipients from our department become faculty members in other institutions, they usually run their own undergraduate research 
programs and mentor undergraduate students thanks to their experiences as graduate students in our department. There are many occasions in our department where our SURGE scholars mix and interact with our own doctoral students, and this encourages our SURGE scholars to move on to graduate studies. About half of our SURGE scholars move on to graduate studies after they receive their bachelor's degrees, whereas only about one quarter of our non-SURGE mathematics bachelor's degree recipients move on to graduate studies.

One of the primary goals of our SURGE program has been to prepare our students to enter STEM workforce or to continue to graduate school. We have been quite successful in the latter as half of our SURGE scholars move to graduate studies. Depending on the economy and other factors, there are also mathematically-talented undergraduate students who prioritize joining STEM workforce instead of continuing to doctoral programs. The Dallas-Fort Worth metropolitan area provides many opportunities for our mathematics undergraduate students to have careers in industry. We feel that we can increase the opportunities for such students with an additional year of training, and for this reason we have been collaborating with other units in our institution to start various BS-MS fast-track degree programs. Our BS-MS fast-track degree program in cooperation with the Biomedical Engineering program will start in the fall semester of 2018. We expect some SURGE students to be enrolled in the BS-MS fast-track programs in the future. We plan to extend the BS-MS fast track degree with an additional concentrated training in Statistics and later also in Data Sciences, as our recent faculty hiring has been concentrating on Statistics and Data Sciences. We have also been collaborating with the UTA Department of Computer Science and Engineering to establish a joint PhD degree program in the Mathematical and Computational Sciences, with the goal of providing additional future opportunities for our SURGE scholars.

The success in our doctoral program, as in many other doctoral institutions, has shifted educational funding from master's students to doctoral students. In the past, many institutions including ours, were accepting students to doctoral programs only after the receipt of a master's degree. It is now possible to start a doctoral program by enrolling in the BS-to-PhD option, by having only a bachelor's degree in the intended field. Hence, the students with the intent of having a terminal master's degree do not have many funding opportunities in doctoral granting departments. An option such as the BS-MS fast-track degree shortens the time to a degree, 
enhances funding possibilities, and improves the employability of students in STEM who do not intend to receive doctoral degrees.

\section{References:}

[1]. W. Y. Velez, J. W. Maxwell, and C. Rode, Report on the 2013-2014 new doctoral recipients, the American Mathematical Society, 2015, available at url:

www.ams.org/profession/data/annual-survey/2014Survey-NewDoctorates-Report.pdf [2]. A. Jackson, UT Arlington wins AMS Exemplary Program Award, Notices of the AMS, Vol. 60, pp. 618-621 (2013).

[3]. B. V. Laden, Serving emerging majority students, New Directions for Community Colleges, Fall 2004, Vol. 127, pp. 5-19 (2004).

[4]. A. P. McGlynn, Transfers from four-year to two-year colleges grow, Education Digest, December 2006, Vol. 72, Issue 4, pp. 60-64 (2006). 